\title{
Terminalia L. (Combretaceae) do Estado de Pernambuco, Brasil ${ }^{1}$
}

\author{
- Rayane de Tasso Moreira Ribeiro $^{2,3,4}$, Maria Iracema Bezerra Loiola ${ }^{3} \mathrm{e}$ \\ Margareth Ferreira de Sales ${ }^{2}$
}

Recebido: 23.09.2017; aceito: 2.04.2018

\begin{abstract}
Terminalia L. (Combretaceae) in Pernambuco State, Brazil). This study consists in the taxonomic survey of Terminalia for the State of Pernambuco. It was based on the morphological analysis of specimens deposited in national herbaria, specialized bibliography and images of type-collections. For the State, five species of Terminalia were recorded: T. amazonia (J.F. Gmel.) Exell., T. glabrescens Mart., T. januariensis DC., T. mameluco Pickel and T. oblonga (Ruiz \& Pav.) Steud. Terminalia species occur preferentially in dense ombrophilous forest in the Atlantic Forest domain. Terminalia amazonia and T. glabrescens represent new occurrences for the State. Only T. januariensis and T. oblonga were recorded in Conservation Units in the State of Pernambuco.
\end{abstract}

Keywords: conservation, diversity, Myrtales, Northeast Brazil

RESUMO - (Terminalia L. (Combretaceae) do Estado de Pernambuco, Brasil). Este trabalho consiste no levantamento taxonômico de Terminalia para o Estado de Pernambuco. Baseou-se na análise morfológica de espécimes depositados em herbários nacionais, bibliografia especializada e imagens de coleções-tipo. Para o Estado foram registradas cinco espécies de Terminalia: T. amazonia (J.F. Gmel.) Exell., T. glabrescens Mart., T. januariensis DC., T. mameluco Pickel e T. oblonga (Ruiz \& Pav.) Steud.). As espécies de Terminalia ocorrem preferencialmente em floresta ombrófila densa no domínio Mata Atlântica. Terminalia amazonia e T. glabrescens representam novas ocorrências para o Estado. Apenas T. januariensis e T. oblonga foram registradas em Unidades de Conservação no Estado de Pernambuco.

Palavras-chave: conservação, diversidade, Myrtales, Nordeste do Brasil

\section{Introdução}

Combretaceae está inserida na ordem Myrtales e compreende 14 gêneros e cerca de 500 espécies, com distribuição nas regiões tropicais e subtropicais do mundo, tendo como centro de diversidade o continente Africano (Stace 2010, APG IV 2016). No Brasil, a família está representada por cinco gêneros e 64 espécies, sendo 13 endêmicas (Flora do Brasil 2020 2017).

Combretaceae subdivide-se em Strephonematoideae Engl. \& Diels, com ovário semi-ínfero, e sem representantes na flora brasileira, e Combretoideae, com ovário ínfero, e cerca de 490 táxons na flora neotropical. Combretum Loefl. e Terminalia L. destacam-se por incluirem o maior número de espécies (Engler \& Diels 1900, Exell \& Stace 1966).
Terminalia abrange cerca de 200 espécies com distribuição pantropical (Stace 2010). Seus representantes se caracterizam pelo hábito arbóreo, folhas simples e alternas, usualmente aglomeradas no ápice dos ramos e flores bissexuadas ou unissexuadas, apétalas. Os frutos são betulídeos, complanados ou arredondados, 2-5 alados ou angulosos (Marquete 1984, Stace 2010, Soares Neto et al. 2014).

Na medicina popular, Terminalia fagifolia Mart. destaca-se devido suas propriedades antiulcerogênicas e antioxidantes, enquanto $T$. actinophylla apresenta ações anti-inflamatórias, sedativas e antidiarreica (Pádua et al. 2013, Nunes et al. 2014).

Estudos taxonômicos e moleculares têm sugerido alterações taxonômicas em Combretaceae. Maurin et al. (2010) sustentam a monofilia de Combretum Loefl., Langucularia (L.) C.F.Gaertn., enquanto,

1. Parte da Tese de Doutorado da primeira Autora

2. Universidade Federal Rural de Pernambuco, Departamento de Biologia, Rua Dom Manoel de Medeiros, s/n, Dois Irmãos, 52171-900 Recife, PE, Brasil

3. Universidade Federal do Ceará, Campus do Pici, Departamento de Biologia, Laboratório de Sistemática e Ecologia Vegetal, Herbário EAC, Prof. Prisco Bezerra, s/n, bloco 906, 60440-900 Fortaleza, CE, Brasil

4. Autora para correspondência: rayanetasso@gmail.com 
Buchenavia Eichler, Conocarpus L. e Terminalia L. seriam táxons parafiléticos, corroborando o posicionamento de Tan et al. (2002). Segundo Maurin et al. (2010), baseado em sequências de genes nucleares e plastidiais (ITS, rbcL, psaA e ycf3), os representantes de Buchenavia deveriam ser transferidos para Terminalia. Entretanto, Stace (2010) e a Flora do Brasil 2020 (2017) consideram os dois gêneros como válidos, posicionamento seguido nesse trabalho.

A distinção morfológica entre Terminalia e Buchenavia é evidenciada em diversos estudos recentes realizados, como os de Stace (2010), Soares Neto et al. (2014) e Ribeiro et al. (2017), com base em caracteres reprodutivos. De forma geral, Terminalia diferencia-se de Buchenavia por apresentar flores com lobos do cálice conspícuos (vs. lobos do cálice inconspícuos), fruto betulídeo seco ( $v s$. fruto drupáceo carnoso), além da presença de alas nos frutos ( $v s$. ausência de alas nos frutos).

No Brasil, as espécies de Terminalia foram tratadas em listagens ou floras regionais e estaduais. Dentre essas, destacam-se os estudos de Marquete (1984), Marquete \& Valente (1997) e Marquete et al. (2003) com espécies da região Sudeste; Linsigen et al. (2009) com espécies da região Sul. Especificamente no Nordeste brasileiro, os representantes de Terminalia foram estudados apenas no Estado do Ceará, no qual Soares Neto et al. (2014) registraram quatro espécies. Destaca-se que no levantamento florístico das Combretaceae ocorrentes na Paraíba, Loiola et al. (2009) não registraram nenhuma espécie de Terminalia nativa, sendo o gênero representado apenas pela espécie cultivada Terminalia catappa L. (Flora do Brasil 2020 2017).

Este estudo tem como objetivo registrar o levantamento das espécies de Terminalia em Pernambuco, incluindo descrições, ilustração e mapa de distribuição geográfica.

\section{Material e métodos}

O estudo baseou-se na análise comparativa de espécimes depositados nos herbários EAC, IPA, MO, NY, PEUFR, SP, SPSF, cujas siglas estão de acordo com Thiers (continuamente atualizado). As identificações foram realizadas com o auxílio de bibliografia especializada (Marquete 1984, Marquete et al. 2003, Stace 2010) e análise de imagens de coleções-tipo, disponíveis online nos sítios dos herbários BR, F, G, M, P, SP e SPSF.
A terminologia para a descrição dos caracteres morfológicos vegetativos e reprodutivos baseou-se em Radford et al. (1974); e para designar o padrão de nervação em Hickey (1973). As descrições do gênero e espécies foram baseadas no material examinado.

Os mapas de distribuição das espécies foram gerados através do programa Quantum GIS 2.16.0 (QGIS 2017). Quando as coordenadas geográficas associadas à localidade das coletas estavam ausentes nas etiquetas das exsicatas, utilizou-se as coordenadas do município obtidas a partir da ferramenta geoLoc (CRIA 2017).

\section{Resultados e Discussão}

Terminalia está representado no Estado de Pernambuco por cinco espécies: T. amazonia (J.F. Gmel.) Exell., T. glabrescens Mart., T. januariensis DC., T. mameluco Pickel e T. oblonga (Ruiz \& Pav.) Steud.), sendo que destas, duas são endêmicas do Brasil. Ressalte-se que T. amazonia e T. glabrescens constituem novas ocorrências para o Estado de Pernambuco. Registrou-se, ainda, a ocorrência de T. catappa L., espécie exótica naturalizada. No entanto, essa espécie não foi tratada no presente estudo.

As espécies de Terminalia foram encontradas preferencialmente em ambientes mais úmidos como a floresta ombrófila densa (mata úmida ou brejos de altitude), na mesorregião da Zona da Mata pernambucana (IBGE 2017). Apenas T. januariensis e T. oblonga foram registradas em unidades de conservação no Estado de Pernambuco.

Tais observações demonstram a necessidade de estudos com ênfase na avaliação da conservação do grupo para o Estado de Pernambuco e Brasil, bem como de um maior esforço amostral, visando novos registros dos representantes de Combretaceae nos diferentes tipos vegetacionais do território pernambucano.

Tratamento taxonômico

Terminalia L., Syst. Nat. 12. (2): 674. 1767.

Árvore. Folhas alternas, frequentemente reunidas no ápice dos ramos, glandulares ou não. Domácias em geral ausentes. Inflorescências em espigas, terminais e/ou axilares. Flores bissexuais. Cálice 5-lobado, lobos desenvolvidos e agudos, reflexos ou não. Pétalas ausentes. Estames 10, inseridos em dois verticilos; 
anteras versáteis. Disco nectarífero geralmente desenvolvido, piloso. Fruto betulídeo, arredondado ou complanado, seco, 2-(4-)5-alado.

Terminalia abrange cerca de 200 espécies com distribuição pantropical, ocorrendo nas regiões tropicais das Américas, África, Oceania e Ásia, sendo este último continente o que apresenta maior número de espécies e uma grande diversidade morfológica (Stace 2010). Nos Neotrópicos, o gênero está representado por 34 espécies, sendo que destas, 23 ocorrem no Brasil e cinco no Estado de Pernambuco (Flora do Brasil 2020 2017).

Chave para identificação das espécies de Terminalia ocorrentes em Pernambuco

1. Folhas coriáceas, ápice arredondado; glândulas 2, na junção da lâmina com o pecíolo

1. T. amazonia

1. Folhas cartáceas a subcoriáceas, ápice agudo a acuminado; glândulas ausentes

2. Domácias marsupiformes com tufos de tricomas rufescentes na axila das nervuras secundárias com a principal; fruto 5 -alado 2. T. glabrescens

2. Domácias ausentes; fruto 2-alado

3. Folhas oblongas a obovado-oblongas; frutos com alas arredondadas ou subtriangulares 5. T. oblonga

3. Folhas elípticas; frutos com alas subelípticas a oblongas

4. Folhas glabras; espigas $10 \mathrm{~cm}$ compr., axilares ou terminais; alas 2-2,3 cm compr.

3. T. januariensis

4. Folhas com indumento seríceo, em ambas as faces; espigas 4-8 cm compr., axilares; alas $0,9-1,2 \mathrm{~cm}$ compr.

4. T. mameluco

1. Terminalia amazonia (J.F. Gmel.) Exell., Fl. Suriname, 3(1): 173. 1935.

Figuras 1, 2a-b

Árvore, glabra. Folha ca. 6-6,2 × 3,8 cm, coriácea, lâmina obovada, glabra, ápice arredondado, base atenuada; nervação eucamptódroma, 5 pares de nervuras secundárias; pecíolo ca. $0,5 \mathrm{~mm}$; glândulas 2, na junção da lâmina com o pecíolo; domácias ausentes. Inflorescências 6,5-9,4 cm compr., densifloras, axilares; bractéola ca. $1 \mathrm{~mm}$, oval; botão floral ca. 2-3 × $2 \mathrm{~mm}$; flores não observadas. Fruto ca. $0,7 \times 1,3 \mathrm{~cm}, 4$-alado, alas desiguais, 2 alas ca. $0,6 \times 0,7 \mathrm{~cm}$ e 2 menores ca. $0,5 \times 0,1 \mathrm{~cm}$, região central $0,6 \times 0,2 \mathrm{~cm}$; pedicelo frutífero não observado.

Material examinado: BRASIL. Pernambuco: Camaragibe, Pau Ferro, lado direito da estrada de Aldeia, 18-XII-1951 (bot., fr.), Ducke \& Lima 77 (EAC, IPA).

Terminalia amazonia é reconhecida pelas folhas coriáceas com ápice arredondado, com duas glândulas na junção da lâmina com o pecíolo, nervação eucamptódroma com 5 pares de nervuras secundárias, fruto 4-alado, com 2 alas maiores e 2 menores, respectivamente. Segundo Stace (2010), a espécie distribui-se do México, América Central e na América do Sul até a Bolívia. No Brasil segundo Stace (2010) e Flora do Brasil 2020 (2017) ocorre apenas nos seguintes Estados amazônicos: Acre, Amazonas, Amapá, Pará e do Maranhão, constituindo-se na primeira referência para Pernambuco, além de ser um evidente exemplo de disjunção amazônico-nordestina (Andrade-Lima 1966). Registrada apenas em floresta ombrófila densa (figura 1). Coletada com frutos no mês de dezembro. Conhecida popularmente como "imbirindiba".

2. Terminalia glabrescens Mart., Flora 20(2 Beibl.): 124. 1837.

Figuras 1, 2c-e

Árvore ca. $18 \mathrm{~m}$, indumento seríceo, recoberta por tricomas ferrugíneos. Folha 5,1-6,9 × 1,6-2,7 cm, cartácea, lâmina elíptica ou obovada, glabra a esparsamente serícea, ápice agudo, base atenuada; nervação eucamptódroma-broquidódroma, 6 pares de nervuras secundárias; pecíolo 1,2-1,3 cm, glândulas ausentes; domácias marsupiformes com tufos de tricomas rufescentes na axila das nervuras secundárias com a principal. Inflorescências 8,4-10,3 cm compr., densifloras, axilares; bractéola não observada; botão floral ca. 3-4 × $2 \mathrm{~mm}$. Flores 2,5-3,5 × 2,5-3 mm, brancas ou esverdeadas; hipanto inferior 1-1,5 $\times 1-1,5 \mathrm{~mm}$, viloso-tomentoso; hipanto superior 1-2,5 × 2,5-3 mm, campanulado; lobos do cálice $0,5-0,6 \times 0,6-0,8 \mathrm{~mm}$, curto-triangulares; filetes do verticilo interno $2,8-3,5 \mathrm{~mm}$, filetes do verticilo externo 2,5-3 mm; anteras 0,4-0,5 × 0,5-0,6 mm, orbiculares; disco nectarífero 0,4-0,5 mm compr., aneliforme, margem livre, pubescente; ovário 0,4-0,6 × 0,3-0,4 mm; estilete 3,5-4 mm, filiforme; 
estigma obtuso. Fruto 1,8-2,2 × 0,5-0,7 cm, 5-alado, alas desiguais, 2 alas mais largas que a região central do fruto e 3 menores; região central ca. $1 \times 1 \mathrm{~mm}$; pedicelo frutífero $1-2 \mathrm{~cm}$.

Material examinado: BRASIL. Pernambuco: Floresta, Serra Negra, 2-XII-1950 (fl.), Andrade-Lima 50-729 (IPA).

Material adicional examinado: BRASIL. CEARÁ: Tianguá, margem da estrada, 23-IX-1978 (fr.), $A$. Fernandes \& P. Bezerra s.n. (EAC 5002).

Terminalia glabrescens pode ser reconhecida e diferenciada de T. amazonia, espécie mais próxima, pelos ramos com coloração ferrugínea (vs. ramos glabros), nervação eucamptódroma-broquidódroma (vs. eucamptódroma), domácias marsupiformes com tufos de tricomas rufescentes ( $v s$. domácias ausentes) e fruto 5-alado ( $v s .4$-alado), com alas desiguais. A espécie foi registrada para o Brasil, Bolívia e Paraguai (Stace 2010). Em território brasileiro, ocorre em todas as regiões (Flora do Brasil 2020 2017). Cabe ressaltar que Stace (2010) identificou a coleção Ducke \& Lima 77 como $T$. glabrescens; no entanto, ao realizarmos um estudo mais detalhado, verificamos que se trata de T. amazonia. Esse é o primeiro registro para a espécie no Estado de Pernambuco, onde foi encontrada em vegetação de floresta ombrófila densa (figura 1). Coletada com flores em dezembro.

3. Terminalia januariensis DC., Prodr. 3: 11. 1828. Figuras 1, 2f-g

Árvore ca. 25 malt., glabra. Folhas 4,3-8,7×2,3-4,2 cm, subcoriáceas, lâmina elíptica a obovada, ápice agudo, base atenuada, glabra; nervação eucamptódromabroquidódroma, 6 pares de nervuras secundárias; pecíolo 0,5-1,7 cm, glândulas e domácias ausentes. Inflorescência ca. 10 cm compr., axilares ou terminais; bractéola, botões florais e flores não observados. Fruto ca. $2 \times 3,5 \mathrm{~cm}, 2$-alado; alas 2-2,3 × 1,4-1,5 cm, subelípticas, mais largas que o região central do fruto; região central 1,9-2,2 × 0,5-0,6 cm; pedicelo frutífero $10 \mathrm{~mm}$.

Material examinado: BRASIL. PernAmbuco: Floresta, Serra Negra, 2-VII-1952 (fr.), M. Magalhães 4801 (EAC, IPA); Nazaré da Mata, 28-II-1956 (fr.), J. Coelho de Moraes 1336 (SP, SPSF).

Nesse estudo, considerou-se Terminalia januariensis, como uma espécie de difícil reconhecimento, devido à estreita similaridade com T. mameluco e a quase inexistência de material disponível para análise. A similaridade entre as duas espécies também é reportada por Stace (2010). No entanto, T. januariensis é reconhecível através das folhas glabras ( $v s$. folhas seríceas), inflorescências com cerca $10 \mathrm{~cm}$ compr., axilares ou terminais (vs. inflorescências 4-8 cm compr., axilares) e fruto 2-alado com alas 2-2,3 cm compr. (vs. alas 0,9-1,2 cm compr.). Espécie endêmica do Brasil, restrita às regiões Nordeste (Bahia e Pernambuco) e Sudeste do país (Espírito Santo, Minas Gerais, Rio de Janeiro e São Paulo) (Stace 2010, Flora do Brasil 2020 2017). Segundo Marquete (2003) e Stace (2010), trata-se de uma espécie ameaçada, sendo representada por árvores de grande porte e encontrada em mata úmida. Em Pernambuco, apresenta registro apenas em vegetação

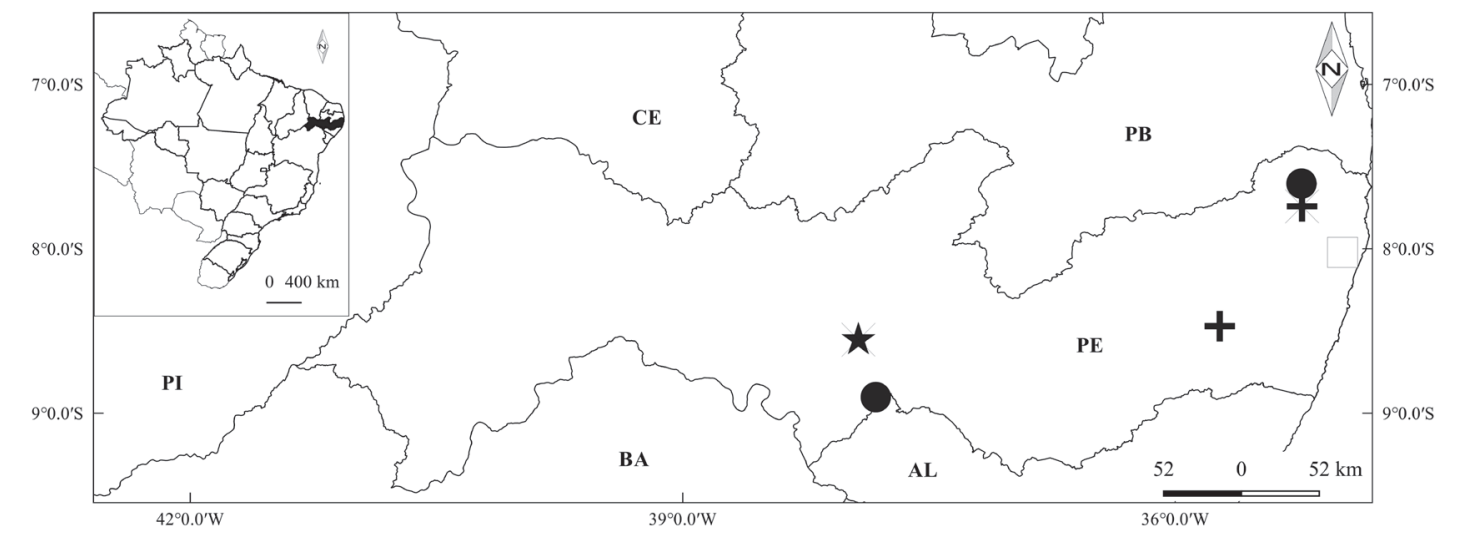

Figura 1. Distribuição de Terminalia no Estado de Pernambuco, Brasil. $\square$ Terminalia amazonia. $\star$ T. glabrescens. $\chi$ T. januariensis. + T. mameluco. T. oblonga.

Figure 1. Distribution of Terminalia in Pernambuco State, Brazil. $\square$ Terminalia amazonia. $\star$ T. glabrescens. $\chi T$. januariensis. $\mathbf{+}$ T. mameluco. T. oblonga. 

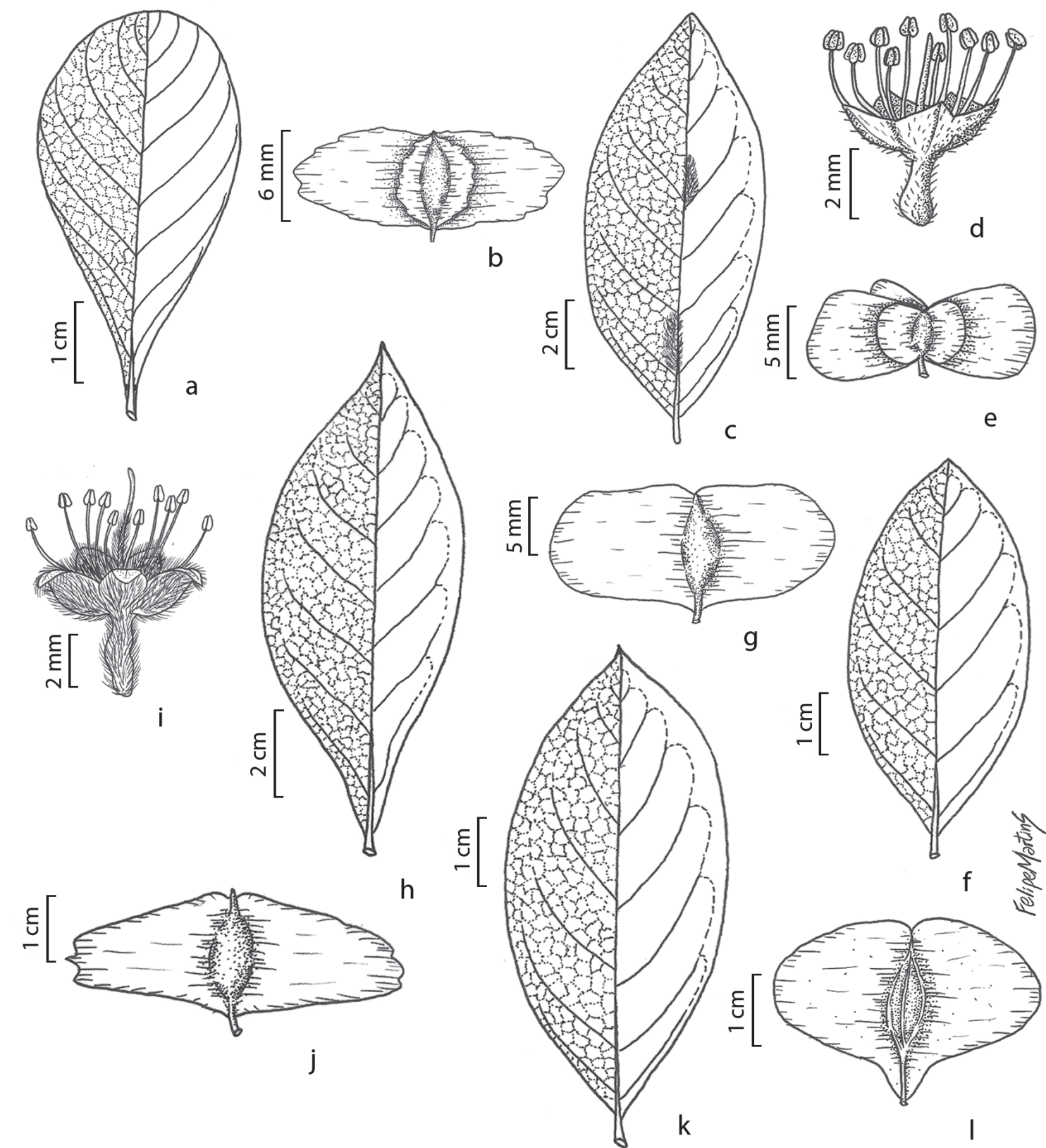

Figura 2. a-b. Terminalia amazonia (A. Ducke 77). a. Folha, b. Fruto. c-e. T. glabrescens. c. Face abaxial da folha com domácias marsupiformes protegidas por tufos de tricomas rufescentes (Andrade-Lima 50-729). d. Flor (Andrade-Lima 50-729). e. Fruto (A. Fernandes \& P. Bezerra s.n.). f-g. T. januariensis (M. Magalhães 4801). f. Folha. g. Fruto. h-j. T. mameluco (Andrade-Lima 67-4938). h. Folha. i. Flor. j. Fruto. k-1. T. oblonga (M.J.N. Rodal 569). k. Folha. 1. Fruto.

Figure 2. a-b. Terminalia amazonia (A. Ducke 77). a. Leaf, b. Fruit. c-e. T. glabrescens. c. Leaf, detail of the abaxial surface with marsupiform domatia protected by tufts of rufescent trichomes (Andrade-Lima 50-729). d. Flower (Andrade-Lima 50-729). e. Fruit (A. Fernandes \& P. Bezerra s.n.). f-g. T. januariensis (M. Magalhães 4801). f. Leaf. g. Fruit. h-j. T. mameluco (Andrade-Lima 67-4938). h. Leaf. i. Flower. j. Fruit. k-1. T. oblonga (M.J.N. Rodal 569). k. Leaf, 1. Fruit. 
de floresta ombrófila densa (figura 1). Registrada na Reserva Biológica de Serra Negra. Encontrada com frutos entre fevereiro e julho.

\section{Terminalia mameluco Pickel, Arq. Bot. Estado São}

Paulo 3: 200. 1958.

Figuras 1, 2h-j

Árvore ca. $8 \mathrm{~m}$ de alt. Folha 5,8-6,1 ×2,3-2,7 cm, lâmina elíptica a obovada, cartácea, serícea em ambas as faces, ápice agudo a acuminado, base atenuada; nervação broquidódroma, 5-8 pares de nervuras secundárias; pecíolo 1,1-1,3 cm, glândulas e domácias ausentes. Inflorescência 4-8 $\mathrm{cm}$ compr., espigas densifloras, axilares; bractéola 1 , com 2,5-3 $\times 0,8-1 \mathrm{~mm}$, cimbiforme; botão floral 3-4,5 × 1,5-2,5 mm, capitado. Flores 5-6 × 2-3 mm, amareladas; hipanto inferior 3-3,5 $\times 1-1,5 \mathrm{~mm}$, elíptico; hipanto superior $5 \times 2-3 \mathrm{~mm}$, campanulado; lobos do cálice ca. 1,5 × 1,5 mm, triangulares, reflexos; filetes do verticilo interno $3-3,5 \mathrm{~mm}$, filetes do verticilo externo ca. $4 \mathrm{~mm}$; anteras $0,6-0,7 \times 0,3-0,6 \mathrm{~mm}$, cordiformes; disco nectarífero ca. 1,2 mm compr., aneliforme, margem livre, glabrescente a pubescente; ovário 0,8-1,5 mm compr.; estilete ca. $5 \mathrm{~mm}$, linear, pubescente na porção basal até metade do comprimento; estigma truncado. Fruto 1,8-2 × 3,1-3,8 cm, 2-alado; alas 0,9-1,2 × 1,4-2 mm, oblongas ou subtriangulares; região central 1,6-2 × 0,5-0,7 mm; pedicelo frutífero 4,2-4,5 mm compr.

Material examinado: BRASIL. Pernambuco: Bonito, 10-II-1967 (fl., fr.), Andrade-Lima 67-4938 (EAC, IPA); Nazaré da Mata, I.1955 (ff.), Coelho de Moraes 1338 (holótipo, SP; isótipo, SPSF).

Terminalia mameluco pode ser reconhecida pelas folhas elípticas a obovadas, com indumento seríceo em ambas as faces; inflorescências 4-8 cm compr., axilares e fruto 2-alado, com alas 0,9-1,2 cm compr., oblongas ou subtriangulares. A espécie é endêmica do leste do Brasil, com registro nas regiões Nordeste e Sudeste do país (Flora do Brasil 2020 2017). Em Pernambuco, foi encontrada em vegetação de floresta ombrófila densa (figura 1). Coletada com flores nos meses de janeiro e fevereiro.

5. Terminalia oblonga (Ruiz \& Pav.) Steud. Nomencl.

Bot. (ed. 2) 2: 668. 1841.

Figuras 1, 2k-1

Árvore ca. $13 \mathrm{~m}$ de alt. Folhas 6,9-14,7×2,3-6,5 cm, lâmina oblonga a obovada-oblonga, subglabra, cartácea, ápice agudo a acuminado, base atenuada; nervação broquidódroma, 5-7 pares de nervuras secundárias; pecíolo 0,7-1,4 cm; glândulas e domácias ausentes. Inflorescência $6-11,3 \mathrm{~cm}$, subcapitadas, axilares. Bractéola, botão floral e flores não observadas. Fruto 2,4-2,6 × 4-5 cm, 2-alado; alas 2,3-2,5 × 1,6-2,1 cm, arredondadas a subtriangulares; região central ca. $2,4 \times 0,6 \mathrm{~cm}$; pedicelo frutífero $0,5-3 \mathrm{~mm}$.

Material examinado: BRASIL. Pernambuco: Aliança, Mata do Engenho Cuieras, I.2006 (fr.), C.G. Lopes 689 (PEUFR); Inajá, Reserva Biológica de Serra Negra, 4-VI-1995 (fr.), M.J.N. Rodal et al. 569 (NY, PEUFR); 20.VII.1995 (fr.), M.J.N. Rodal et al. 610 (MO, NY, PEUFR); 29.XI.1996, L.M. Nascimento \& D.S. Pimentel 19 (PEUFR).

Terminalia oblonga é uma espécie bem definida e caracteriza-se por apresentar folhas com 6,9-14,7 cm compr., oblongas a obovado-oblongas e fruto 2-alado com alas arredondadas a subtriangulares. A espécie tem registro nas Américas Central e do Sul (Stace 2010). No Brasil, é registrada nas regiões Norte e Nordeste do país (Flora do Brasil 2020 2017). Em Pernambuco, T. oblonga ocorre em área com predomínio de mata úmida, em floresta ombrófila densa. Registrada na Reserva Biológica de Serra Negra. Encontrada com frutos nos meses de janeiro e junho.

\section{Agradecimentos}

A CAPES (Coordenação de Aperfeiçoamento de Pessoal de Nível Superior) pela bolsa de Doutorado concedida à primeira Autora; a Felipe Martins Guedes pela elaboração das ilustrações; Dra. Nilda Marquete Ferreira da Silva por todos os ensinamentos e bibliografia concedidos à primeira autora. Ao $\mathrm{CNPq}$ (Conselho Nacional de Desenvolvimento Científico e Tecnológico) pelas bolsas de produtividade concedidas a Margareth Ferreira de Sales e Maria Iracema Bezerra Loiola. A toda equipe do Laboratório de Sistemática e Ecologia Vegetal (LASEV-UFC, http://www.lasevufc. com/) e Laboratório de Taxonomia Vegetal (LATAXUFRPE), em especial Luciana Silva Cordeiro e Leidiana Lima dos Santos, pelo auxílio em algumas etapas de elaboração deste trabalho.

\section{Literatura citada}

Andrade-Lima, D. 1966. Contribuição ao estudo do paralelismo da flora amazônico nordestina. Boletim Técnico do Instituto de Pesquisas Agronômicas 19: 1-30. 
Angiosperm Phylogeny Group IV. 2016. An update of the Angiosperm Phylogenetic Group classification for the orders and families of flowering plants: APG IV. Botanical Journal of the Linnean Society 181: 1-20.

CRIA. 2017. Geoloc. Disponível em http://splink.cria.org. br/ (acesso em 23-VIII-2017).

Engler, H.G.A. \& Diels, L. 1900. Combretaceae - Combretum. In: H.G.A. Engler (ed.). Monographien afrikanischer PflanzenFamilien und Gattungen. Engelmann. v. 3, pp. 1-116.

Exell, A.W. \& Stace, C.A. 1966. Revision of the Combretaceae. Boletim Sociedade Broteriana 40: 5-25.

Flora do Brasil 2020 em construção. 2017. Jardim Botânico do Rio de Janeiro. Disponível em http:// floradobrasil.jbrj.gov.br/ (acesso em 28-VIII-2017).

Hickey, L.J. 1973. Classification of the architecture of dicotyledonous leaves. American Journal of Botany 60: 17-33.

IBGE (Instituto Brasileiro de Geografia e Estatística. 2017. Cidades. Disponível em http://www.ibge.gov.br/ estadosat/perfil.php? sigla=PE (acesso em 2-V-2017).

Linsigen, L.V., Cervi, A.C. \& Guimarães, O. 2009. Sinopse taxonômica da família Combretaceae R. Brown na Região Sul do Brasil. Acta Botanica Brasilica 23: 738-750.

Loiola, M.I.B., Rocha, E.A., Baracho, G.S. \& Agra, M.F. 2009. Flora da Paraíba: Combretaceae. Acta Botanica Brasilica 23: 330-342.

Marquete, N.F.S. 1984. Combretaceae do estado do Rio de Janeiro. Subtribo Terminaliineae. Rodriguésia 36: 91-104.

Marquete, N.F.S. \& Valente, M.C. 1997. Combretaceae. In: M.C.M. Marques \& H.F. Martins (orgs.). Flora do estado do Rio de Janeiro. Albertoa 4: 13-51.

Marquete, N.F.S., Teixeira, J. \& Valente, M.C. 2003. Terminalia L. (Combretaceae) na Região Sudeste do Brasil. Bradea 16: 99-123.

Maurin, O., Chase M.K., Jordaan, M. \& Vanderbank, M. 2010. Phylogenetic relationships of Combretaceae inferred from nuclear and plastid DNA sequence data: implications for generic classification. Botanical Journal of the Linnean Society 162: 453-476.
Nunes, P.H.M., Martins, M.C.C., Oliveira, R.C.M., Chaves, M.H., Sousa, E.A., Leite, J.R.S.A., Véras, L.M. \& Almeida, F.R.C. 2014. Gastric Antiulcerogenic and Hypokinetic Activities of Terminalia fagifolia Mart. \& Zucc. (Combretaceae). BioMed Research International 2014: 1-14.

Pádua, P.F., Dihl, R.R., Lehmann, M., Abreu, B.R., Richter, M.F. \& Andrade, H.H. 2013. Genotoxic, antigenotoxic and phytochemical assessment of Terminalia actinophylla ethanolic extract. Food and Chemical Toxicology 62: 521-527.

Quantum GIS Development Team. 2017. Quantum GIS Geographic Information System. Open Source Geospatial Foundation Project. Disponível em http:// qgis.osgeo.org/ (acesso em 2-II-2017).

Radford, A.E., Dickson, W.C., Massey, J.R. \& Bell, C.R. 1974. Vascular plant systematics. Harper \& Row, New York, pp. 1-899.

Ribeiro, R.T.M., Loiola, M.I.B. \& Sales, M.F. 2017. Flora do Espírito Santo: Subtribo Terminaliinae (Combretaceae). Rodriguésia 68: 1547-1557.

Soares Neto, R.L., Cordeiro, L.S. \& Loiola, M.I.B. 2014. Flora do Ceará, Brasil: Combretaceae. Rodriguésia 65: 685-700.

Stace, C.A. 2010. Combretaceae. Flora Neotropica 107. The New York Botanical Garden Press, New York, pp. 1-369.

Tan, F.X., Shi, S.H., Zhong, Y., Gong, X. \& Wang, Y.G. 2002. Phylogenetic relationships of Combretoideae (Combretaceae) inferred from plastid, nuclear gene and spacer sequences. Journal of Plant Research 115: 475-481

Thiers, B. (continuously updated). Index Herbariorum: a global directory of public herbaria and associated staff. New York Botanical Garden's Virtual Herbarium. Disponível em http://sweetgum.nybg.org/ih/ (acesso em 28-VIII-2017). 